\title{
Role of Prostaglandins in Neuroinflammatory and Neurodegenerative Diseases
}

\author{
Isabel Vieira de Assis Lima, ${ }^{1}$ Leandro Francisco Silva Bastos, ${ }^{2,3}$ \\ Marcelo Limborço-Filho, ${ }^{2}$ Bernd L. Fiebich, ${ }^{4,5}$ \\ and Antonio Carlos Pinheiro de Oliveira ${ }^{1,4}$
}

${ }^{1}$ Department of Pharmacology, Federal University of Minas Gerais, Avenida Antonio Carlos, 6627, 31270-901 Belo Horizonte, MG, Brazil

${ }^{2}$ Department of Physiology and Biophysics, Federal University of Minas Gerais, Avenida Antonio Carlos, 6627, 31270-901 Belo Horizonte, Brazil

${ }^{3}$ Department of Psychology and Neuroscience, Muenzinger Building, Colorado University of Colorado Boulder, Avenida, Boulder, CO 80309-0354, USA

${ }^{4}$ Department of Psychiatry and Psychotherapy, University of Freiburg Medical School, Hauptstraße 5, 79104 Freiburg, Germany

${ }^{5}$ VivaCell Biotechnology GmbH, Ferdinand-Porsche-Straße 5, 79211 Denzlingen, Germany

Correspondence should be addressed to Antonio Carlos Pinheiro de Oliveira, antoniooliveira@icb.ufmg.br

Received 15 December 2011; Accepted 5 April 2012

Academic Editor: Lúcia Helena Faccioli

Copyright (C) 2012 Isabel Vieira de Assis Lima et al. This is an open access article distributed under the Creative Commons Attribution License, which permits unrestricted use, distribution, and reproduction in any medium, provided the original work is properly cited.

Increasing data demonstrates that inflammation participates in the pathophysiology of neurodegenerative diseases. Among the different inflammatory mediators involved, prostaglandins play an important role. The effects induced by prostaglandins might be mediated by activation of their known receptors or by nonclassical mechanisms. In the present paper, we discuss the evidences that link prostaglandins, as well as the enzymes that produce them, to some neurological diseases.

\section{Neuroinflammation and Neurodegeneration}

Neuroinflammation plays a key role in the progression or resolution of pathological conditions. Inflammatory responses in the brain parenchyma have been associated with the etiopathogenesis of different neurological disorders, including central nervous system (CNS) infection, brain ischemia, multiple sclerosis, Alzheimer's disease, and Parkinson's disease [1-7]. Then, it is presently clear that neuroinflammation is a key feature shared by many neurodegenerative disorders $[8,9]$.

Different CNS cells, such as microglia, astrocytes, oligodendrocytes, and neurons produce a plethora of inflammatory mediators, which act either in a paracrine or an autocrine fashion, leading to an intricate cross-talk between these different cell types. Among these mediators, many studies have demonstrated that CNS cells produce prostanoids and that these mediators might contribute to the normal CNS function or to enhance the neuroinflammatory and neurodegenerative processes [10]. Herein, we review the current knowledge on the role of prostaglandins, as well as the enzymes that synthesize them, in neuroinflammatory and neurodegenerative diseases.

\section{Roles of Prostaglandins in Neuroinflammation: In Vitro and In Vivo Evidences}

Due to the variety of prostaglandins presently known, it is reasonable to speculate that these lipid mediators might play different roles in the CNS. Below, we describe some in vivo and in vitro data with regard to the potential role of specific prostanoids in neuroinflammation. 
2.1. $P G E_{2}$. To date, three prostaglandin (PG) E synthases (PGESs) have been characterized: the microsomal PGESs (mPGES-1 and mPGES-2) and the cytosolic PGES (cPGES) [11-14]. mPGES-1 is an inducible enzyme and is expressed also in activated microglia $[15,16]$. There are at least four characterized $\mathrm{PGE}_{2}$ receptors, namely, EP1, EP2, EP3, and EP4. This prostaglandin modulates the expression of inflammatory mediators by microglial cells. For example, $\mathrm{PGE}_{2}$ and EP agonists inhibited the expression of inducible nitric oxide synthase (iNOS) and nitric oxide (NO) generation [17] and enhanced the expression of cyclooxygenase (COX)2 induced by lypopolysaccharide (LPS) in cultured microglia [18]. Moreover, an EP2 agonist inhibited interleukin (IL)$1 \beta$ release by cultured primary rat microglia stimulated with LPS, although no reduction of this cytokine was observed with EP1, EP3, and EP4 agonists [19].

Intraperitoneal injection of LPS increased the expression of EP4 receptors in microglial cells and in the hippocampus of mice [20]. Interestingly, activation of EP4 receptors reduced the expression of different cytokines, COX-2 and iNOS in BV-2 and primary mouse microglial cells [20].

2.2. $P G D_{2}$. $P G D_{2}$ has also been shown to be important in neuroinflammatory conditions. A 6-day infusion of LPS in the fourth cerebral ventricle of rats enhanced the $\mathrm{PGD}_{2}$ production in the brain [21]. It has been shown that $\mathrm{PGD}_{2}$ produced by microglia acts on DP1 receptors of astrocytes, leading to astrogliosis. Moreover, oligodendroglial apoptosis was reduced by hematopoietic prostaglandin D synthase (HPGDS) inhibitor and in HPGDS-null mice, suggesting an important effect of $\mathrm{PGD}_{2}$ in demyelination in twitcher mice, a model of Krabbe disease [22]. Expression of DP1 and HPGDS is also increased in the brains of patients with Alzheimer's disease [23].

$\mathrm{PGD}_{2}$ also induced apoptosis of mouse oligodendrocyte precursor $(\mathrm{mOP})$ cells, what could interfere in the demyelination process that occurs in multiple sclerosis [24]. It was shown that mice deficient in lipocalin-PGDS reveal an increased number of apoptotic neurons and olygodendrocytes, suggesting a protective role of lipocalin-type PGDS in the genetic demyelinating mouse twitcher [25].

2.3. 15 -Deoxy- $\Delta^{12,14}$-Prostaglandin $J_{2}\left(15 d-P G J_{2}\right)$. $15 \mathrm{~d}-\mathrm{PGJ}_{2}$ is a metabolite of $\mathrm{PGD}_{2}$ and is formed from $\mathrm{PGD}_{2}$ by the elimination of two molecules of water. At least some effects mediated by $15 \mathrm{~d}-\mathrm{PGJ}_{2}$ are mediated by activation of the peroxisome proliferator-activated receptors (PPARs) $\gamma$. This prostaglandin has been shown to inhibit NO and tumor necrosis factor (TNF)- $\alpha$ production as well as expression of major histocompatibility complex (MHC) class II in activated microglia, suggesting that this prostaglandin might be important to modulate microglia functions [26]. Similar effects, such as downregulation of iNOS and cytokines, have also been observed in astrocytes [27].

2.4. $P_{G}$. Few studies were carried out to investigate the role of $\mathrm{PGI}_{2}$ in the CNS. In general, these studies suggest a neuroprotective role for $\mathrm{PGI}_{2}$ against different stimuli.
For example, enhancement of $\mathrm{PGI}_{2}$ synthesis in neuronglia cultures by adenoviral gene transfer of PGI synthase (PGIS) reduces the expression of different inflammatory mediators induced by LPS, such as TNF- $\alpha$ [28], and $\mathrm{PGI}_{2}$ receptor ligands prevented the death of hippocampal neurons induced by high oxygen, xanthine + xanthine oxidase, or serum deprivation [29]. Interestingly, 15-deoxy-(16m-tolyl)-17,18,19,20-tetranorisocarbacyclin methyl ester, a selective central type $\mathrm{PGI}_{2}$ receptor ligand, reduced brain damage induced by middle cerebral artery occlusion [30].

2.5. $P G F_{2 \alpha}$. In rat primary neuronal culture, hypoxia increased $\mathrm{PGF}_{2 \alpha}$ content. Importantly, previous addition of this prostaglandin to the culture medium exacerbated hypoxic injury [31]. $\mathrm{PGF}_{2 \alpha}$ reduced TNF- $\alpha$ in primary spinal cord cultures stimulated with LPS [32]. In a model of unilateral middle cerebral artery occlusion, knockout (KO) mice to $\mathrm{FP}$, the receptor for $\mathrm{PGF}_{2 \alpha}$, have less neurological deficit and smaller infarct volumes [33]. The $\mathrm{KO}$ animals were also less sensitive to excitotoxicity induced by unilateral intrastriatal $\mathrm{N}$-methyl-D-aspartate injection. In agreement with that, in the same model, the FP agonist latanoprost increased neurological deficit and infarct size in wildtype (WT) mice [33].

\section{Roles of Prostaglandins in Neurodegenerative Diseases}

As previously mentioned, there are strong evidences that inflammation contributes to etiopathogenesis of neuroinflammatory and neurodegenerative diseases. Below, we discuss the involvement of prostaglandins in these neuropathological conditions.

3.1. Multiple Sclerosis (MS). A neuroinflammatory component is very evident in the etiopathogenesis of MS. MS is an autoimmune demyelinating disorder characterized by distinct episodes of neurologic deficits attributable to white matter lesions. It is the most common of the demyelinating disorders, which affects predominantly northern Europeans. The disease becomes clinically apparent at any age, although onset in childhood or after 50 years of age is relatively rare. Women are affected twice as often as men. In most individuals with MS, the illness shows relapsing and remitting episodes of neurologic deficits. The frequency of relapses tends to decrease during the course of the disease, but there is a steady neurologic deterioration in a subset of patients [34].

Modeling clinical aspects of any human disease in rodents and cells is a big challenge in all fields of research. However, it is especially more challenging to model MS, because this is an exclusively human disease, its etiopathogenesis is unknown, and this disease is multifaceted, which occur in a relapsing-remitting manner. As the toxin-induced models of demyelination such as those induced by cuprizone, ethidium bromide and lysolecithin are important to understand demyelination and remyelination but do not resemble the human disease as efficiently as the autoimmune model (experimental autoimmune encephalomyelitis EAE), this 
paper will be focused on the roles played by prostaglandins in this model because of its presumed higher predictive validity [35].

3.1.1. Phospholipase $A_{2} \quad\left(P L A_{2}\right)$ and COX. There is a large body of evidence demonstrating the role played by prostanoids in the onset and progression of EAE in a wide variety of animal models as well as in in vitro studies. Within the last decade, some studies have demonstrated that cytosolic $\mathrm{PLA}_{2}\left(\mathrm{cPLA}_{2}\right)$ plays a key role in the etiopathogenesis of EAE [36-39]. There are evidences supporting distinct roles played by different isoforms of $\mathrm{PLA}_{2}$ in the onset or progression of EAE [40]. CPLA 2 plays a role in the onset of EAE, calcium-independent $\mathrm{PLA}_{2}$ in the onset and progression, and secretory type II PLA 2 in the later remission phase. Immunohistochemical labeling of $\mathrm{CPLA}_{2}$ was shown in either immune or endothelial cells in the spinal cord lesions of mice with EAE induced by myelin oligodendrocyte glycoprotein (MOG). Both preemptive and therapeutic treatments with a selective $\mathrm{CPLA}_{2}$ inhibitor resulted in marked reduction in the onset and progression of EAE. Accordingly, the reduced clinical score parallels with reduced spinal protein concentration of COX-2 and both gene expression and protein concentrations of dozens of inflammatory mediators, including several cytokines and chemokines which are implicated with the etiopathogenesis of EAE [36]. Moreover, selective inhibition of $\mathrm{cPLA}_{2 \alpha}$ prevents EAE and suppresses Th1 and Th17 responses [38]. cPLA $_{2 \alpha}$ inhibitors diminish the ability of antigen-presenting cells to induce antigen-specific effector T-cell proliferation and inflammatory cytokine production, inhibit microglial activation, and increase oligodendrocyte survival [39]. The latter study also showed that if $\mathrm{cPLA}_{2 \alpha}$ inhibitors are administered at the peak of disease or during remission-relapsingremitting model-, the subsequent relapse is abolished. Consistently with these pharmacological studies, a genetic study showed that $\mathrm{CPLA}_{2 \alpha}$-deficient mice are resistant to EAE [37].

COX-1 and -2 are upregulated in the CNS of animals in different EAE models [36, 38, 41]. Accordingly, different selective and nonselective inhibitors of COX isoforms induce beneficial effects in different animal models of EAE. EAE onset is delayed if diet is supplemented with acetylsalicylic acid shortly after its induction in Lewis rats [42]. Indomethacin, another non-selective COX inhibitor, attenuates the progression of EAE [43].

3.1.2. $P G E_{2}$. $\mathrm{PGE}_{2}$ seems to be the eicosanoid which is more strongly implicated with EAE onset and progression. Bolton and colleagues investigated the CNS concentrations of $\mathrm{PGE}_{2}$, 6-oxo-PGF $1 \alpha$, and $\mathrm{PGF}_{2 \alpha}$ in acute EAE-affected guinea pigs [44]. They showed that a $\mathrm{PGE}_{2}$ concentration increase in spinal cord and cerebellum precedes EAE onset, whereas the other two prostanoids were found to peak after the observation of the first clinical signs of EAE. The behavioral syndrome associated with EAE is also preceded by increased CNS concentration of $\mathrm{PGE}_{2}$ in mice [45]. A wide screening that examined the correlation between many arachidonic acid (AA) pathway products and EAE onset and progression showed that $\mathrm{PGE}_{2}$ (concomitantly with its receptors EP1, EP2, and EP4) is synthesized more markedly than other eicosanoids [46], suggesting an important role in exacerbating EAE. However, dual roles played by $\mathrm{PGE}_{2}$ have been recently shown in mouse EAE. PGE 2 exacerbates Th1 and Th2 responses via EP2 and EP4 receptors during mouse EAE onset and protects the brain from immune cell infiltration via EP4 receptor [47].

mPGES-1 upregulation occurs in microglia/macrophages in the spinal cord lesions of mice with EAE induced by MOG as well as in brain tissues from MS patients. mPGES-1-deficient mice exhibit a better clinical score and suppressed Th1 and Th17 responses when compared with those of nongenetically modified control mice after EAE induction [46]. Regarding the untoward gastric and cardiovascular effects induced by COX inhibitors [48], there is an eagerness to discover compounds that target mPGES-1 for treating inflammatory diseases [49-51] because this enzyme is downstream to COX-2 in AA pathway.

3.1.3. $15 d-P G J_{2}$. Systemic treatment with $15 d-P G J_{2}$ inhibits EAE progression in mice, and this is associated with reduced demyelination, neuroinflammation, IL-12 production by macrophage/microglial cells, T-cell proliferation, and IL12-induced T-cell responses [52]. Moreover, pretreatment with this agonist of PPARy delays the onset of EAE and reduces the spinal cord infiltration of $\mathrm{CD}^{+} \mathrm{T}$ cells and macrophages [53]. $15 \mathrm{~d}-\mathrm{PGJ}_{2}$ suppresses the production of cytokines and/or chemokines in cultured $\mathrm{T}$ cells, microglia, and astrocytes [53-55]. Providing further support to the role played by $15 \mathrm{~d}-\mathrm{PGJ}_{2}$ in EAE etiopathogenesis, it was shown that PPAR $\gamma$ antagonists reverse the inhibition of EAE clinical signs and Th1 response by this cyclopentanone prostaglandin [56].

3.1.4. Other Prostaglandins. As there is a correlation between increased spinal PGDS concentration and the initiation of relapsing phase of EAE, it has been suggested a role played by this isomerase in this phenomenon [57]. Indeed, $\mathrm{PGD}_{2}$ is released from mast cells in allergic reactions, and it is suggested to modulate allergic inflammation $[58,59]$. On the other hand, a more recent study showed that $\mathrm{PGD}_{2}, \mathrm{PGI}_{2}$ and 5-lipoxygenase pathways are suppressed in the acute phase of EAE and returns to constitutive levels in the chronic phase [46]. However, in a relapsing-remitting model, $\mathrm{PGD}_{2}$ remained unaffected throughout all phases [41].

3.2. Alzheimer's Disease ( $A D)$. The first evidences supporting a role played by inflammation on $\mathrm{AD}$ onset rose up in the late 1980s, when many signs of inflammation in postmortem brains from $\mathrm{AD}$ patients were observed, such as activated lymphocytes and microglial cells in plaque and tangle lesions, presence of complement proteins, cell lysis, and opsonisation of debris [60-64].

3.2.1. $P L A_{2}$ and COX. It was hypothesized that the longterm use of nonsteroidal anti-inflammatory drugs (NSAIDs) could reduce the risk for $\mathrm{AD}$ or delay disease onset. Indeed, 
McGeer et al. [65] observed a clear negative correlation between the prevalence of $\mathrm{AD}$ in general population versus that in rheumatoid arthritis patients taking NSAIDs, mainly salicylates. Reinforcing this evidence, a clinical trial conducted shortly afterwards, showed that treatment with indomethacin, a nonselective COX inhibitor, improves cognitive deficits in AD patients [66]. Since then, epidemiological studies have been showing either beneficial or detrimental effects induced by COX inhibitors on $\mathrm{AD}$ risk and delay of onset, though beneficial effects are mostly observed [67]. Despite controversy, these studies clearly show that prostanoids play an important role in $\mathrm{AD}$ etiopathogenesis.

$\mathrm{cPLA}_{2}$, which cleaves AA from cellular membrane phospholipids, is elevated in $\mathrm{AD}$ brain [68]. The cyclooxygenation and subsequent isomerization of AA produces prostaglandins, which regulate immune responses and neurotransmission $[69,70]$. Accordingly, increased expression of COX-1 and -2 is observed in AD-affected brains [71, 72]. One of the most versatile products of this cascade is $\mathrm{PGE}_{2}$, which is produced by glial cells and neurons.

3.2.2. $P G E_{2}$. An increased expression of mPGES-1 and mPGES-2 is observed in the brain of $\mathrm{AD}$ brains [73, 74]. Moreover, patients with probable $\mathrm{AD}$ have higher cerebrospinal fluid (CSF) concentrations of $\mathrm{PGE}_{2}$ than agematched control subjects [75]. It has been shown that $\mathrm{PGE}_{2}$ increases amyloid precursor protein (APP) gene expression and production in vitro [76-78]. This effect is inhibited by immunosuppressants in astrocytes [77] and is associated with EP2 receptor activation in microglial cells [78]. On the other hand, there is evidence supporting an antiinflammatory role played by $\mathrm{PGE}_{2}$ mediated by $\mathrm{EP} 4$ receptor in LPS-stimulated cultured microglial cells [20]. However, $\mathrm{PGE}_{2}$ increases APP production via both EP2 and EP4 receptors (but not via $\mathrm{EP} 1$ and $\mathrm{EP} 3$ ones) both in vitro and in vivo [76, 79]. Hoshino et al. [76] showed that $\mathrm{PGE}_{2}$-dependent internalization of EP4 receptor increases $\gamma$ secretase activity, which in turn leads to higher proteolysis of APP.

In transgenic mice overexpressing APP, selective inhibition of COX-2 blocks amyloid $\beta$ (A $\beta$ )-induced suppression of hippocampal long-term potentiation (LTP) and memory function independently of reductions in $A \beta 42$ and inflammatory cytokines, but markedly dependent on $\mathrm{PGE}_{2}$ concentrations, showing an additional mechanism by which NSAIDs may protect against $\mathrm{AD}$ progression and an important synaptic role of $\mathrm{PGE}_{2}$ in this setting [80]. EP2 receptors are important mediators of $\mathrm{PGE}_{2}$ actions on electrophysiological properties of hippocampal neurons, as $\mathrm{EP}^{-/-}$mice exhibit cognitive deficits in social memory tests associated with a deficit in long-term depression in hippocampus [81]. Pharmacological studies corroborate these previously mentioned findings. Either exogenous or endogenous $\mathrm{PGE}_{2}$, but not exogenously applied $\mathrm{PGD}_{2}$ or $\mathrm{PGF}_{2 \alpha}$, regulates hippocampal neuronal plasticity $[69,70]$.

3.2.3. $P G D_{2}$ and $15 d-P G J_{2}$. One of the first studies which assessed prostaglandins concentrations in postmortem cerebral cortices of probable $\mathrm{AD}$ patients showed that only $\mathrm{PGD}_{2}$ was increased in comparison with age-matched control subjects [82]. Indeed, PGDS expression was found to be localized in microglial cells surrounding senile plaques, and DP1 receptor expression was observed in microglial cells and astrocytes within senile plaques in human $\mathrm{AD}$ brains. In Tg2576 transgenic mice- a model of AD disease- the DP1 receptor expression increases in parallel with $\mathrm{A} \beta$ deposition [23].

As $15 \mathrm{~d}-\mathrm{PGJ}_{2}$ induces neuronal apoptosis [83], it was initially suggested that this prostanoid is associated with neurodegeneration. However, it was shown afterwards that $15 \mathrm{~d}-$ $\mathrm{PGJ}_{2}$ reduces microglial production of NO, IL- 6 , and TNF- $\alpha$ induced by $\mathrm{A} \beta 40$, which suggests anti-inflammatory indirect neuroprotective effect [84]. Accordingly, not only $15 \mathrm{~d}-\mathrm{PGJ}_{2}$, but also troglitazone and ciglitazone, other compounds known to activate PPAR $\gamma$ and attenuate the A $\beta$-induced impairment of hippocampal LTP in vitro, supporting a possible beneficial effect on $\mathrm{AD}$ progression.

3.3. Parkinson's Disease (PD). PD is the second most common neurodegenerative disease, characterized by abnormal motor symptoms such as stiffness, postural instability, slowness of movement, resting tremor, and bradykinesia. The neuropathological features of PD are progressive death of dopaminergic neurons in the substantia nigra $(\mathrm{SN})$ pars compacta that project to the striatum. The exact cause of this cell death is not clear, but recent studies have shown that the process may involve inflammatory reactions, in addition to oxidative stress, mitochondrial dysfunction, neural excitotoxicity, and insufficient neurotrophic factors [85-87].

It is known that, in the $\mathrm{SN}$ of PD brains, microglia is activated [5], and its activation has been strongly associated with CNS pathology of $\mathrm{PD}$, by production of proinflammatory and cytotoxic factors, such as cytokines, chemokines, NO, reactive oxygen species (ROS), and AA metabolites $[88,89]$.

3.3.1. $P L A_{2}$ and COX. It has been shown that mice carrying a mutation of the $\mathrm{CPLA}_{2}$ gene, leading to an absence of ${ }_{\text {cPLA }}$ activity, are resistant to 1-methyl-4-phenyl-1,2,3,6tetrahydropyridine (MPTP), a precursor to 1-methyl-4phenylpyridinium $\left(\mathrm{MPP}^{+}\right)$-induced neurotoxicity, a wellknown model of PD [90]. Dopamine receptor activation also increased CPLA ${ }_{2}$ activity in a rat model of PD [91].

Many data demonstrated also an alteration of COX-2 expression in PD. In fact, different studies have shown an upregulation of COX-2 in animal models of PD [92-94]. COX-2 increased expression has been also demonstrated in the $\mathrm{SN}$ of postmortem $\mathrm{PD}$ specimens in comparison to normal controls [95, 96]. Moreover, it has been shown that COX inhibition $[93,94,97,98]$ and COX transgenic ablation [99-101] in in vivo models of PD increased survival of dopaminergic neurons. However, this effect was not observed in all studies. Rofecoxib, a COX-2 inhibitor, did not change MPTP-induced neurodegeneration and, paradoxically, caused a significantly augmented basal prostaglandin production [92]. 
Regular use of NSAIDs is associated with a lower risk of PD compared with nonregular users of these drugs [85, 102]. However, this is still controversial, since recent studies could not demonstrate a protective effect of NSAIDs in PD [103-105]. Considering that these drugs might have other mechanisms of action unrelated to COX inhibition, it is important to evaluate the effect of specific compounds in the prevention or treatment of $\mathrm{PD}$.

3.3.2. $P G E_{2}$. It has been observed that $\mathrm{PGE}_{2}$ is significantly elevated in the CSF and SN of PD patients in comparison to control subjects. Moreover, incubation of slices of $\mathrm{SN}$ with $\mathrm{AA}$ induced an increased production of $\mathrm{PGE}_{2}$ synthesis, suggesting an enhancement of the enzymes responsible to its production [106].

Release of aggregated $\alpha$-synuclein, a major component of Lewy bodies in PD, after neuronal damage, may activate microglia. This activation could, in turn, lead to production of proinflammatory mediators, such as $\mathrm{PGE}_{2}$ [107], contributing to the progression of nigral neurodegeneration. A pretreatment of primary mesencephalic neuron-glia mouse cultures with $\alpha$-synuclein enhances the production of $\mathrm{PGE}_{2}$. Apparently, phagocytosis of $\alpha$-synuclein activates NADPH oxidase, which produces ROS, and has a crucial role in microglial activation and associated neurotoxicity [107].

In primary mesencephalic mixed neuron-microglia cultures, $\mathrm{MPP}^{+}$, a neurotoxin that causes dopaminergic neuronal death, induced $\mathrm{PGE}_{2}$ production. However, this effect was not observed in enriched microglia and enriched neuron cultures, indicating that is necessary an interaction between microglia and neurons for $\mathrm{MPP}^{+}$-induced increase of the $\mathrm{PGE}_{2}$ production, probably due to COX-2 activity. Moreover, $\mathrm{PGE}_{2}$ was not enhanced neither in enriched astroglia nor in neuron-astroglia cultures [94]. Conversely, $\mathrm{PGE}_{2}$ was significantly reduced in the hippocampus, striatum, and cortex of animals injected with 6-hydroxydopamine (6OHDA) [108].

It has been shown that EP receptors are expressed differently in the SN. To date, in the rat, EP1 is restricted to dopaminergic neurons, while EP3 is expressed exclusively by nondopaminergic cells. On the other hand, EP2 is localized to both dopaminergic and nondopaminergic cells [109]. In rats, EP1, but not EP2 and EP3 receptor antagonists, reduced the dopaminergic neuronal death induced by 6OHDA, suggesting an important effect of EP1 receptor in the neurotoxicity induced by $\mathrm{PGE}_{2}$ [109]. Also, culture of dopaminergic neurons displayed EP2 receptors after 6OHDA neurotoxicity, and butaprost, a selective EP2 agonist, significantly increased survival of tyrosine hydroxylase positive cells, suggesting a possible neuroprotective role of EP2 of activation [110].

Interestingly, in comparison to microglia obtained of WT animals, microglia of EP2 KO mice reveal an enhanced capacity to clear aggregated $\alpha$-synuclein in human mesocortex tissue of patients with Lewy body disease. Moreover, $\mathrm{EP}^{-/-}$mice were more resistant to neurotoxicity induced by MPTP, an effect that is associated with attenuated formation of aggregated $\alpha$-synuclein in the SN and striatum [111].
3.3.3. $P G D_{2}, P G J_{2}$, and Other Prostaglandins. $P \mathrm{PJ}_{2}$ and its metabolites might alter the process of protein folding and aggregation, contributing to the development of PD. In human neuroblastoma SK-N-SH cells, $\mathrm{PGJ}_{2}$ disrupts the structural integrity of microtubules and actin filaments [112]. In vitro, this molecule also hindered the polymerization of highly purified tubulin from bovine brain [113]. Interestingly, in cells treated with $\mathrm{PGJ}_{2}$, microtubule/endoplasmatic reticulum collapse coincides with the formation of protein aggregates, such as ubiquitinated proteins and $\alpha$-synuclein [113].

In mouse and human neuroblastoma cells, as well as in rat primary embryonic mesencephalic cultures, $\mathrm{PGA}_{1}$, $\mathrm{PGD}_{2}, \mathrm{PGJ}_{2}$, and its metabolite $\Delta^{12}-\mathrm{PGJ}_{2}$ induced accumulation of ubiquitinated proteins and cell death [114]. $\mathrm{PGE}_{2}$ only exhibited neurotoxic effects at high concentrations. The ubiquitination induced by $\Delta^{12}-\mathrm{PGJ}_{2}$ might be due to inhibition of ubiquitin C-terminal hydrolase (UCH) L3 and UCH-L1, implicating in an alteration of deubiquitinating enzymes, possibly contributing to the accumulation and aggregation of ubiquitinated proteins, what leads to inflammation associated with the neurodegenerative process [114]. Modification of UCH-L1, an enzyme that functions predominantly during monoubiquitin recycling in the ubiquitin-proteosome system, by cyclopentenone prostaglandins, induced unfolding and aggregation of the protein. Therefore, the deleterious effect of COX-2 in PD could be due to the production of cyclopentenone prostaglandins [115].

In addition to that, $\mathrm{PGA}_{1}$ has been shown to reduce nuclear factor kappa $\mathrm{B}$ translocation to the nucleus, caspase 3 activation, and apoptosis of human dopaminergic SH-SY5Y cells induced by rotenone [116].

3.4. Amyotrophic Lateral Sclerosis (ALS). ALS is a progressive neurodegenerative condition characterized by the selective death of motor neurons [117]. This neuropathological condition can be classified as familial, in which mutations in the enzyme superoxide dismutase-1 (SOD1) can occur, or as sporadic, which encompasses $90 \%$ of ALS patients [118]. Neuroinflammation seems to play an important role in the progress of this disorder. In ALS, microglia activation and proliferation is observed in regions where there is neuron loss, like motor cortex, motor nuclei of the brainstem and corticospinal tract. Microglia might be essential for the motor neuron toxicity [119].

3.4.1. $\mathrm{PLA}_{2}$ and COX. It has been shown that $\mathrm{CPLA}_{2}$ is expressed in astrocytes and motor neurons of the spinal cord of transgenic mice carrying the gene encoding a mutant form of human SOD1 $[120,121]$. In agreement with that, $\mathrm{CPLA}_{2}$ immunoreactivity was also observed in the spinal cord of human SOD1-mutated familial ALS and in sporadic ALS patients [120, 122].

An increase in COX-2 expression is observed in the spinal cord of SOD1 ${ }^{\mathrm{G} 93 \mathrm{~A}}$ transgenic mice $[123,124]$ and human cases of ALS $[125,126]$. Postmortem examination of the ventral horn of the spinal cord of sporadic ALS patients 
revealed that COX-2 immunoreactivity was increased in motor and interneurons, as well as in glia, in comparison with non-ALS controls [127]. On the other hand, COX-1 expression was detected in microglia, but not in neurons, of ALS and controls tissues, albeit no difference was observed between the two groups of patients [127].

Few attempts have also been made to elucidate the effect induced by COX inhibitors in models of ALS. In organotypic spinal cord cultures, the COX-2 selective inhibitor SC236 significantly reduced the excitotoxic damage of motor neurons induced by threo-hydroxyaspartate, a compound that inhibits astroglial transport of glutamate [128]. Therefore, it is possible that COX-2 might be involved in the excitotoxicity induced by glutamate.

Moreover, in vivo studies also suggested that COX might be a potential target for ALS treatment. It has been shown that traditional NSAIDs and COX-2 inhibitors reduced different pathological features developed by SOD $1^{\mathrm{G} 93 \mathrm{~A}}$ transgenic mice, such as loss of motor neurons and glial activation in the spinal cord, motor impairment and weight loss, as well as these compounds prolonged the survival of the animals [120, 129-131]. Considering these evidences, Minghetti [132] suggested that COX-2 enhancement could be deleterious in ALS not only due to the enhancement of glutamate release by $\mathrm{PGE}_{2}$ [133], but also because of the ROS produced by COX peroxidase activity.

On the other hand, Almer et al. [134] have shown a drastically reduced $\mathrm{PGE}_{2}$ production in the spinal cord of transgenic SOD $1^{\mathrm{G} 93 \mathrm{~A}} / \mathrm{COX}-1^{-/-}$mice, suggesting a minor role for COX-2 in the production of $\mathrm{PGE}_{2}$ in the disease. Moreover, deficiency of COX-1 did not affect motor neuron loss and survival of the animals [134]. These results challenge the concept that COX-2 is the main enzyme involved in ALS.

3.4.2. $P G E_{2}$ and $15 d-P G J_{2} . P G E_{2}$ is elevated in the spinal cord of SOD $1^{\mathrm{G} 93 \mathrm{~A}}$ mice [130] and in the serum and CSF of ALS patients [127, 135], though the levels of this prostaglandin did not correlate with clinical state of the patients [135].

The role of $\mathrm{PGE}_{2}$ was further investigated in in vitro models of ALS. In an organotypic spinal cord slice model, motor neuronal death induced by D, L-threo-hydroxyaspartate is reduced by $\mathrm{PGE}_{2}$, as well as butaprost and sulprostone, EP2 and EP3 receptor agonists, respectively [136]. Interestingly, in the same study, SC58236, a COX-2 inhibitor, also reduced motor neuron loss.

EP2 receptor expression is increased in astrocytes and microglia of SOD $1^{\mathrm{G} 93 \mathrm{~A}}$ mice and in astrocytes of human ALS spinal cord. Deficiency of EP2 receptor in SOD1 ${ }^{\mathrm{G} 93 \mathrm{~A}}$ mice increased the survival and grip strength in comparison with $\mathrm{SOD} 1^{\mathrm{G} 93 \mathrm{~A}} / \mathrm{EP}^{+/+}$and SOD $1^{\mathrm{G} 93 \mathrm{~A}} / \mathrm{EP} 2^{+/-}$mice. The absence of EP2 receptor also reduced the production of different inflammatory mediators in this animal model of ALS [124].

Recently, it has been shown that mPGES-1 is enhanced in the spinal cord of SOD1 $1^{\mathrm{G} 93 \mathrm{~A}}$ in comparison with WT mice. Interestingly, AAD-2004, a molecule that inhibits mPGES-1 and free radical formation, reduced microglia activation and motor neuron loss, as well as it improved motor function and increased survival [137].

$15 \mathrm{~d}-\mathrm{PGJ}_{2}$ immunoreactivity is increased not only in motor neurons, but also in astrocytes and reactive microglia in the spinal cord of ALS patients [138].

3.5. Huntington's Disease (HD). $\mathrm{HD}$ is a progressive neurodegenerative disease that reveals movement disorders and dementia as main features. This pathological condition is an autosomal-dominant pathological condition disease [139, 140]. Although there are evidences that neuroinflammation is present in $\mathrm{HD}$, it is not known whether it contributes to the etiopathogenesis of the disease or whether it is solely an epiphenomenon [141].

It has been shown that in R6/2 mice, an animal model of $\mathrm{HD}$, the number of microglia is reduced in some brain regions in comparison with their WT littermates. Microglia of animals at 14.5 weeks of age were also smaller in size than the same cells in the animals at 7 weeks of age, and they also revealed condensed nucleus and fragmentation of the cytoplasm within processes, suggesting an impaired function of these cells in this pathological condition [142]. On the other hand, activated microglia are present in the neostriatum, cortex, and globus pallidus of HD brains. Importantly, the reactive microglia appeared in association with pyramidal neurons presenting huntingtinpositive intranuclear inclusions [143]. Although a causal link between neuroinflammation and HD onset or progression has not been demonstrated, it is reasonable to assume that microglia might play a role in its development.

3.5.1. COX. Although there are different genetic models of $\mathrm{HD}$, some compounds such as 3-nitropropionic acid (3-NP) and quinolinic acid (QA) are also used to induce striatal neuron toxicity, being therefore considered HD animal models [144-146]. COX-2 immunoreactivity is enhanced in striatal tissues $12 \mathrm{~h}$ after treatment of animals with QA. This enhancement was observed predominantly in neurons and microglia [147].

Chronic treatment with different COX inhibitors, such as rofecoxib, celecoxib, nimesulide, and meloxicam improved spontaneous locomotor activity and the motor performance, as well as these medicines reduced biochemical and mitochondrial alteration induced by QA [148-150]. Naproxen and valdecoxib, two COX inhibitors, also reduced 3-NPinduced motor and cognitive impairment [151]. This study suggested that these effects could be due to a reduction in the oxidative stress induced by the drugs.

Although beneficial effects were observed induced by COX inhibitors in drug-induced models of HD, similar effects are not observed in transgenic mice. For example, administration of acetylsalicylate from weaning did not induce any alteration of rotarod performance and ventricle enlargement N171-82Q mice in comparison with untreated animals. Rofecoxib also did not change motor performance and lifespan of R6/2 mice [152]. On the other hand, acetylsalicylate and celecoxib shortened life expectancy of R6/2 and N171-82Q mice, respectively [152, 153]. 
3.5.2. $P G E_{2}, P G F_{2 \alpha}$, and $P G A_{1}$. Administration of $3-\mathrm{NP}$ enhances $\mathrm{PGE}_{2}$ and $\mathrm{PGF}_{2 \alpha}$ in the striatum $[154,155]$. These prostaglandins are reduced by licofelone, a competitive inhibitor of COX-1, COX-2, and 5-LOX isoenzymes. In addition, this compound reduced the impairment in locomotor activity and motor performance, as well as it reduced apoptotic markers [155]. Expression of COX-2, as well as $\mathrm{PGE}_{2}$ production, is increased in the ipsilateral side compared with the contralateral vehicle-injected side in the striatum and cortex of rats by unilateral intrastriatal injection of QA [156]. Moreover, it has also been shown that QA injection induced EP3-positive striatal neuronal loss, whereas activated microglia expressed EP3 in vivo after excitotoxicity injury [157].

A role for $\mathrm{PGA}_{1}$ has also been suggested. This prostaglandin attenuated DNA fragmentation and neuronal loss and increased dopamine D1 receptor expression induced by QA in the striatum it also reduced the QA-induced activation of nuclear factor kappa B, but not activator protein-1, in this brain region [158].

\section{Discussion}

There is an intricate relationship between neuroinflammation and neurodegeneration. In general, acute inflammation in the CNS is triggered by a neuronal injury or infection and is short-lived. This acute response is believed to have protective aspects, since it could avoid further injury and induce tissue repair [159]. Although an acute stimulus may trigger, for example, oxidative stress, this short-term event would not interfere with long-term neuronal survival [160]. It is known that moderate microglia activation might induce neuroprotective effects, such as to scavenger neurotoxins, remove cell debris and secrete mediators which are important for neuronal survival [160]. Acute activation of these cells is a normal response to injuries, and it contributes to wound healing [161].

On the other hand, chronic neuroinflammation persists for a long time after the initial insult and normally is selfperpetuating [160]. This condition induces neuronal death, and the molecules released by the dead neurons can further activate microglia, which enhances cell death. This vicious cycle, together with the continuous production of factors that activate microglia, contributes to the chronicity of this process.

Again, microglia might play an important role in this long-term process. Intense activation and accumulation of these cells at the site of injury can induce neuronal damage, since they release a variety of neurotoxic substances. For example, the $\mathrm{A} \beta$ protein, which is involved in $\mathrm{AD}$, can activate microglia and lead them to release neurotoxic factors such as NO, TNF- $\alpha$, and superoxide, leading to the progression of this disorder [162]. An interesting finding is that a chronic inflammation induced by the infusion of LPS (a substance that strongly activates microglia) in the brain of rats resembles different features observed in $\mathrm{AD}$ patients [163].

Actually, it is presently not clear why the neuronal or glial cells cannot prevent the chronicity of the inflammatory process. However, it might be due to a plethora of effects. Abnormal synthesis of some proteins by neurons could continuously activate microglia, leading them to the release of neurotoxic factors. Moreover, oxidative stress is another important event that contributes to the neuronal damage observed in chronic neuroinflammation [164]. It is also possible that the senescence of immune system in the CNS could contribute to chronicity of this process. For example, it has been shown that microglia from old transgenic PS1-APP mice release an increased amount of inflammatory mediators and do not phagocytose $A \beta$ properly in comparison to microglia from young mice [165]. Therefore, microglia senescence could play a role in the development of some neurodegenerative conditions $[161,166]$. Despite these facts, the adaptive immune system might also play a role, as it has been shown that it is involved in the etiopathogenesis of PD [167].

In this context, one might assume that the production of lipid mediators, such as prostaglandins, might differently modulate neuroinflammation and neurodegeneration. Considering the roles of prostaglandins and depending on the stage of inflammation, as well as different microenvironments generated by a variety of substances, these lipid mediators could determine the survival or death of neurons.

\section{Conclusion}

Here we summarized the evidences that prostaglandins might play a key role in the etiopathogenesis of neuroinflammatory and neurodegenerative diseases. Prostaglandins have a plethora of actions in CNS cells that differently affect the progress of inflammation and neuronal death or survival. Therefore, inhibition of the production of a specific prostanoid or its action on its receptor would be a better mechanism to control some pathological processes. On the other hand, inhibiting the effects of some prostaglandins could also be deleterious. Thus, further studies are important to make a more complete idea the role of these lipid mediators in neuroinflammation and neurodegeneration. This knowledge might serve to develop pharmacological strategies for the treatment of neurological diseases.

\section{Abbreviations}

$15 \mathrm{~d}-\mathrm{PGJ}_{2}: 15$-deoxy- $\Delta^{12,14}$-prostaglandin $\mathrm{J}_{2}$

3-NP: 3-nitropropionic acid

6-OHDA: 6-hydroxydopamine

AA: $\quad$ Arachidonic acid

AD: $\quad$ Alzheimer's disease

ALS: $\quad$ Amyotrophic lateral sclerosis

$\mathrm{A} \beta: \quad$ Amyloid $\beta$

APP: $\quad$ Amyloid precursor protein

CNS: Central nervous system

COX: Cyclooxygenase

CSF: Cerebrospinal fluid

EAE: Experimental autoimmune

encephalomyelitis

HD: $\quad$ Huntington's disease 
HPGDS: Hematopoietic prostaglandin D synthase

IL: Interleukin

iNOS: Inducible nitric oxide synthase

KO: $\quad$ Knockout

LPS: Lypopolysaccharide

LTP: Long-term potentiation

MHC: Major histocompatibility complex

MOG: Myelin oligodendrocyte glycoprotein

mOP: Mouse oligodendrocyte precursor

mPGES: Microsomal PGE synthase

$\mathrm{MPP}^{+}$: 1-methyl-4-phenylpyridinium

MPTP: 1-methyl-4-phenyl-1,2,3,6tetrahydropyridine

MS: $\quad$ Multiple sclerosis

NO: $\quad$ Nitric oxide

NSAIDs: Nonsteroidal anti-inflammatory drugs

PD: $\quad$ Parkinson's disease

PG: Prostaglandin

PGIS: PGI synthase

$\mathrm{PLA}_{2}$ : Phospholipase $\mathrm{A}_{2}$

PPARs: Peroxisome proliferator-activated receptors

QA: Quinolinic acid

ROS: $\quad$ Reactive oxygen species

SN: $\quad$ Substantia nigra

SOD1: Superoxide dismutase-1

TNF: Tumor necrosis factor

UCH: Ubiquitin C-terminal hydrolase

WT: Wildtype.

\section{Acknowledgments}

The authors acknowledge Fundação de Apoio à Pesquisa do Estado de Minas Gerais (FAPEMIG, Minas Gerais, Brazil) and Pró-Reitoria de Pesquisa (PRPq) da Universidade Federal de Minas Gerais for financial support.

\section{References}

[1] J. K. Andersen, "Oxidative stress in neurodegeneration: cause or consequence?” Nature Medicine, vol. 10, pp. S18-S25, 2004.

[2] J. M. Craft, D. M. Watterson, and L. J. Van Eldik, "Neuroinflammation: a potential therapeutic target," Expert Opinion on Therapeutic Targets, vol. 9, no. 5, pp. 887-900, 2005.

[3] D. W. Dickson, S. C. Lee, L. A. Mattiace, S. H. Yen, and C. Brosnan, "Microglia and cytokines in neurological disease, with special reference to AIDS and Alzheimer's disease," Glia, vol. 7, no. 1, pp. 75-83, 1993.

[4] J. J. Hoozemans, S. M. Chafekar, F. Baas, P. Eikelenboom, and W. Scheper, "Always around, never the same: pathways of amyloid beta induced neurodegeneration throughout the pathogenic cascade of Alzheimer's disease," Current Medicinal Chemistry, vol. 13, no. 22, pp. 2599-2605, 2006.

[5] P. L. McGeer, S. Itagaki, B. E. Boyes, and E. G. McGeer, "Reactive microglia are positive for HLA-DR in the substantia nigra of Parkinson's and Alzheimer's disease brains," Neurology, vol. 38, no. 8, pp. 1285-1291, 1988.
[6] L. Minghetti, M. A. Ajmone-Cat, M. A. De Berardinis, and R. De Simone, "Microglial activation in chronic neurodegenerative diseases: roles of apoptotic neurons and chronic stimulation," Brain Research Reviews, vol. 48, no. 2, pp. 251256, 2005.

[7] M. P. Sherman, J. M. Griscavage, and L. J. Ignarro, "Nitric oxide-mediated neuronal injury in multiple sclerosis," Medical Hypotheses, vol. 39, no. 2, pp. 143-146, 1992.

[8] H. M. Gao and J. S. Hong, "Why neurodegenerative diseases are progressive: uncontrolled inflammation drives disease progression," Trends in Immunology, vol. 29, no. 8, pp. 357$365,2008$.

[9] S. M. Lucas, N. J. Rothwell, and R. M. Gibson, "The role of inflammation in CNS injury and disease," British Journal of Pharmacology, vol. 147, supplement 1, pp. S232-S240, 2006.

[10] M. L. Block and J. S. Hong, "Microglia and inflammationmediated neurodegeneration: multiple triggers with a common mechanism," Progress in Neurobiology, vol. 76, no. 2, pp. 77-98, 2005.

[11] P. J. Jakobsson, S. Thoren, R. Morgenstern, and B. Samuelsson, "Identification of human prostaglandin E synthase: a microsomal, glutathione-dependent, inducible enzyme, constituting a potential novel drug target," Proceedings of the National Academy of Sciences of the United States of America, vol. 96, no. 13, pp. 7220-7225, 1999.

[12] N. Tanikawa, Y. Ohmiya, H. Ohkubo et al., "Identification and characterization of a novel type of membrane-associated prostaglandin E synthase," Biochemical and Biophysical Research Communications, vol. 291, no. 4, pp. 884-889, 2002.

[13] T. Tanioka, Y. Nakatani, N. Semmyo, M. Murakami, and I. Kudo, "Molecular identification of cytosolic prostaglandin $\mathrm{E}_{2}$ synthase that is functionally coupled with cyclooxygenase1 in immediate prostaglandin $\mathrm{E}_{2}$ biosynthesis," Journal of Biological Chemistry, vol. 275, no. 42, pp. 32775-32782, 2000.

[14] K. Watanabe, K. Kurihara, and T. Suzuki, "Purification and characterization of membrane-bound prostaglandin E synthase from bovine heart," Biochimica et Biophysica Acta, vol. 1439, no. 3, pp. 406-414, 1999.

[15] A. C. P. de Oliveira, E. Cadelario-Jalil, H. S. Bhatia, K. Lieb, M. Hull, and B. L. Fiebich, "Regulation of prostaglandin $\mathrm{E}_{2}$ synthase expression in activated primary rat microglia: evidence for uncoupled regulation of mPGES-1 and COX-2," Glia, vol. 56, no. 8, pp. 844-855, 2008.

[16] A. C. de Oliveira, E. Candelario-Jalil, J. Langbein et al., "Pharmacological inhibition of Akt and downstream pathways modulates the expression of COX-2 and mPGES-1 in activated microglia," Journal of Neuroinflammation, vol. 9, article 2, 2012.

[17] L. Minghetti, "Prostaglandin $\mathrm{E}_{2}$ downregulates inducible nitric oxide synthase expression in microglia by increasing cAMP levels," Advances in Experimental Medicine and Biology, vol. 433, pp. 181-184, 1997.

[18] L. Minghetti, A. Nicolini, E. Polazzi, C. Creminon, J. Maclouf, and G. Levi, "Inducible nitric oxide synthase expression in activated rat microglial cultures is downregulated by exogenous prostaglandin $\mathrm{E}_{2}$ and by cyclooxygenase inhibitors," Glia, vol. 19, no. 2, pp. 152-160, 1997.

[19] A. O. Caggiano and R. P. Kraig, "Prostaglandin E receptor subtypes in cultured rat microglia and their role in reducing lipopolysaccharide-induced interleukin- $1 \beta$ production," Journal of Neurochemistry, vol. 72, no. 2, pp. 565-575, 1999.

[20] J. Shi, J. Johansson, N. S. Woodling, Q. Wang, T. J. Montine, and K. Andreasson, "The prostaglandin $\mathrm{E}_{2}$ E-prostanoid 4 receptor exerts anti-inflammatory effects in brain innate 
immunity," Journal of Immunology, vol. 184, no. 12, pp. 7207-7218, 2010.

[21] T. A. Rosenberger, N. E. Villacreses, J. T. Hovda et al., "Rat brain arachidonic acid metabolism is increased by a 6-day intracerebral ventricular infusion of bacterial lipopolysaccharide," Journal of Neurochemistry, vol. 88, no. 5, pp. 1168 1178, 2004.

[22] I. Mohri, M. Taniike, I. Okazaki et al., "Lipocalin-type prostaglandin D synthase is up-regulated in oligodendrocytes in lysosomal storage diseases and binds gangliosides," Journal of Neurochemistry, vol. 97, no. 3, pp. 641-651, 2006.

[23] I. Mohri, K. Kadoyama, T. Kanekiyo et al., "Hematopoietic prostaglandin D synthase and DP1 receptor are selectively upregulated in microglia and astrocytes within senile plaques from human patients and in a mouse model of Alzheimer disease," Journal of Neuropathology \& Experimental Neurology, vol. 66, no. 6, pp. 469-480, 2007.

[24] Z. Xiang, T. Lin, and S. A. Reeves, " $15 \mathrm{~d}-\mathrm{PGJ}_{2}$ induces apoptosis of mouse oligodendrocyte precursor cells," Journal of Neuroinflammation, vol. 4, article 18, 2007.

[25] M. Taniike, I. Mohri, N. Eguchi, C. T. Beuckmann, K. Suzuki, and Y. Urade, "Perineuronal oligodendrocytes protect against neuronal apoptosis through the production of lipocalin-type prostaglandin D synthase in a genetic demyelinating model," Journal of Neuroscience, vol. 22, no. 12, pp. 4885-4896, 2002.

[26] A. Bernardo, G. Levi, and L. Minghetti, "Role of the peroxisome proliferator-activated receptor- $\gamma$ (PPAR- $\gamma$ ) and its natural ligand 15 -deoxy- $\Delta 12,14$-prostaglandin $\mathrm{J}_{2}$ in the regulation of microglial functions," European Journal of Neuroscience, vol. 12, no. 7, pp. 2215-2223, 2000.

[27] N. K. Phulwani, D. L. Feinstein, V. Gavrilyuk, C. Akar, and T. Kielian, "15-Deoxy- $\Delta$ 12,14-prostaglandin $\mathrm{J}_{2}$ (15d$\mathrm{PGJ}_{2}$ ) and ciglitazone modulate Staphylococcus aureusdependent astrocyte activation primarily through a PPAR- $\gamma$ independent pathway," Journal of Neurochemistry, vol. 99, no. 5, pp. 1389-1402, 2006.

[28] M. J. Tsai, S. K. Shyue, C. F. Weng et al., "Effect of enhanced prostacyclin synthesis by adenovirus-mediated transfer on lipopolysaccharide stimulation in neuron-glia cultures," Annals of the New York Academy of Sciences, vol. 1042, pp. 338-348, 2005.

[29] T. Satoh, Y. Ishikawa, Y. Kataoka et al., "CNS-specific prostacyclin ligands as neuronal survival-promoting factors in the brain," European Journal of Neuroscience, vol. 11, no. 9, pp. 3115-3124, 1999.

[30] H. Takamatsu, H. Tsukada, Y. Watanabe et al., "Specific ligand for a central type prostacyclin receptor attenuates neuronal damage in a rat model of focal cerebral ischemia," Brain Research, vol. 925, no. 2, pp. 176-182, 2002.

[31] W. Li, S. Wu, R. W. Hickey, M. E. Rose, J. Chen, and S. H. Graham, "Neuronal cyclooxygenase-2 activity and prostaglandins $\mathrm{PGE}_{2}, \mathrm{PGD}_{2}$, and PGF2 $\alpha$ exacerbate hypoxic neuronal injury in neuron-enriched primary culture," $\mathrm{Neu}$ rochemical Research, vol. 33, no. 3, pp. 490-499, 2008.

[32] C. Brenneis, O. Coste, K. Altenrath et al., "Anti-inflammatory role of microsomal prostaglandin E synthase-1 in a model of neuroinflammation," The Journal of Biological Chemistry, vol. 286, pp. 2331-2342, 2011.

[33] S. Saleem, A. S. Ahmad, T. Maruyama, S. Narumiya, and S. Dore, "PGF $\mathrm{PF}_{2 \alpha}$ FP receptor contributes to brain damage following transient focal brain ischemia," Neurotoxicity Research, vol. 15, no. 1, pp. 62-70, 2009.

[34] A. Compston and A. Coles, "Multiple sclerosis," The Lancet, vol. 359, no. 9313, pp. 1221-1231, 2002.
[35] A. R. Pachner, "Experimental models of multiple sclerosis," Current Opinion in Neurology, vol. 24, no. 3, pp. 291-299, 2011.

[36] A. Kalyvas and S. David, "Cytosolic phospholipase $A_{2}$ plays a key role in the pathogenesis of multiple sclerosis-like disease," Neuron, vol. 41, no. 3, pp. 323-335, 2004.

[37] S. Marusic, M. W. Leach, J. W. Pelker et al., "Cytosolic phospholipase $\mathrm{A}_{2 \alpha}$-deficient mice are resistant to experimental autoimmune encephalomyelitis," Journal of Experimental Medicine, vol. 202, no. 6, pp. 841-851, 2005.

[38] S. Marusic, P. Thakker, J. W. Pelker et al., "Blockade of cytosolic phospholipase $A_{2 \alpha}$ prevents experimental autoimmune encephalomyelitis and diminishes development of Th1 and Th17 responses," Journal of Neuroimmunology, vol. 204, no. 1-2, pp. 29-37, 2008.

[39] P. Thakker, S. Marusic, N.L. Stedman et al., "Cytosolic phospholipase $\mathrm{A}_{2} \alpha$ blockade abrogates disease during the tissue-damage effector phase of experimental autoimmune encephalomyelitis by its action on APCs," Journal of Immunology, vol. 187, no. 4, pp. 1986-1997, 2011.

[40] A. Kalyvas, C. Baskakis, V. Magrioti et al., "Differing roles for members of the phospholipase $A_{2}$ superfamily in experimental autoimmune encephalomyelitis," Brain, vol. 132, no. 5, pp. 1221-1235, 2009.

[41] S. S. Ayoub, E. G. Wood, S. U. Hassan, and C. Bolton, "Cyclooxygenase expression and prostaglandin levels in central nervous system tissues during the course of chronic relapsing experimental autoimmune encephalomyelitis (EAE)," Inflammation Research, vol. 60, no. 10, pp. 919-928, 2011.

[42] P. G. Weston and P. V. Johnston, "Incidence and severity of experimental allergic encephalomyelitis and cerebral prostaglandin synthesis in essential fatty acid deficient and aspirin-treated rats," Lipids, vol. 13, no. 12, pp. 867-872, 1978.

[43] A. T. Reder, M. Thapar, A. M. Sapugay, and M. A. Jensen, "Prostaglandins and inhibitors of arachidonate metabolism suppress experimental allergic encephalomyelitis," Journal of Neuroimmunology, vol. 54, no. 1-2, pp. 117-127, 1994.

[44] C. Bolton, D. Gordon, and J. L. Turk, "A longitudinal study of the prostaglandin content of central nervous system tissues from guinea pigs with acute experimental allergic encephalomyelitis (EAE)," International Journal of Immunopharmacology, vol. 6, no. 2, pp. 155-161, 1984.

[45] Y. Pollak, H. Ovadia, E. Orion, J. Weidenfeld, and R. Yirmiya, "The EAE-associated behavioral syndrome: I. Temporal correlation with inflammatory mediators," Journal of Neuroimmunology, vol. 137, no. 1-2, pp. 94-99, 2003.

[46] Y. Kihara, T. Matsushita, Y. Kita et al., "Targeted lipidomics reveals $\mathrm{mPGES}-1-\mathrm{PGE}_{2}$ as a therapeutic target for multiple sclerosis," Proceedings of the National Academy of Sciences of the United States of America, vol. 106, no. 51, pp. 2180721812, 2009.

[47] Y. Esaki, Y. Li, D. Sakata et al., "Dual roles of $\mathrm{PGE}_{2}-\mathrm{EP} 4$ signaling in mouse experimental autoimmune encephalomyelitis," Proceedings of the National Academy of Sciences of the United States of America, vol. 107, no. 27, pp. 12233-12238, 2010.

[48] G. A. Fitzgerald, "Coxibs and cardiovascular disease," The New England Journal of Medicine, vol. 351, no. 17, pp. 17091711, 2004.

[49] L. F. S. Bastos, A. C. P. de Oliveira, J. C. M. Schlachetzki, and B. L. Fiebich, "Minocycline reduces prostaglandin E 
synthase expression and 8-isoprostane formation in LPSactivated primary rat microglia," Immunopharmacology and Immunotoxicology, vol. 33, no. 3, pp. 576-580, 2011.

[50] E. Candelario-Jalil, A. C. P. de Oliveira, S. Graf et al., "Resveratrol potently reduces prostaglandin $\mathrm{E}_{2}$ production and free radical formation in lipopolysaccharide-activated primary rat microglia," Journal of Neuroinflammation, vol. 4, article 25, 2007.

[51] M. D. Guerrero, M. Aquino, I. Bruno, R. Riccio, M. C. Terencio, and M. Payá, "Anti-inflammatory and analgesic activity of a novel inhibitor of microsomal prostaglandin E synthase-1 expression," European Journal of Pharmacology, vol. 620, no. 1-3, pp. 112-119, 2009.

[52] C. Natarajan and J. J. Bright, "Peroxisome proliferatoractivated receptor-gamma agonist inhibit experimental allergic encephalomyelitis by blocking IL-12 production, IL-12 signaling and Th1 differentiation," Genes and Immunity, vol. 3, no. 2, pp. 59-70, 2002.

[53] A. Diab, C. Deng, J. D. Smith et al., "Peroxisome proliferatoractivated receptor- $\gamma$ agonist 15 -deoxy- $\Delta^{12,14}$-prostaglandin $\mathrm{J}_{2}$ ameliorates experimental autoimmune encephalomyelitis," Journal of Immunology, vol. 168, no. 5, pp. 2508-2515, 2002.

[54] P. D. Storer, J. Xu, J. Chavis, and P. D. Drew, "Peroxisome proliferator-activated receptor-gamma agonists inhibit the activation of microglia and astrocytes: implications for multiple sclerosis," Journal of Neuroimmunology, vol. 161, no. 1-2, pp. 113-122, 2005.

[55] J. Xu and P. D. Drew, "Peroxisome proliferator-activated receptor- $\gamma$ agonists suppress the production of IL-12 family cytokines by activated glia," Journal of Immunology, vol. 178, no. 3, pp. 1904-1913, 2007.

[56] H. P. Raikwar, G. Muthian, J. Rajasingh, C. N. Johnson, and J. J. Bright, "PPAR $y$ antagonists reverse the inhibition of neural antigen-specific Th1 response and experimental allergic encephalomyelitis by Ciglitazone and 15-Deoxy$\Delta$ 12,14-Prostaglandin $\mathrm{J}_{2}$," Journal of Neuroimmunology, vol. 178, no. 1-2, pp. 76-86, 2006.

[57] R. Pedotti, J. J. DeVoss, S. Youssef et al., "Multiple elements of the allergic arm of the immune response modulate autoimmune demyelination," Proceedings of the National Academy of Sciences of the United States of America, vol. 100, no. 4, pp. 1867-1872, 2003.

[58] Y. Fujitani, Y. Kanaoka, K. Aritake, N. Uodome, K. OkazakiHatake, and Y. Urade, "Pronounced eosinophilic lung inflammation and Th2 cytokine release in human lipocalintype prostaglandin D synthase transgenic mice," Journal of Immunology, vol. 168, no. 1, pp. 443-449, 2002.

[59] T. Matsuoka, M. Hirata, H. Tanaka et al., "Prostaglandin $\mathrm{D}_{2}$ as a mediator of allergic asthma," Science, vol. 287, no. 5460, pp. 2013-2017, 2000.

[60] P. L. McGeer, H. Akiyama, S. Itagaki, and E. G. McGeer, "Activation of the classical complement pathway in brain tissue of Alzheimer patients," Neuroscience Letters, vol. 107, no. 1-3, pp. 341-346, 1989.

[61] P. L. McGeer, H. Akiyama, S. Itagaki, and E. G. McGeer, "Immune system response in Alzheimer's disease," Canadian Journal of Neurological Sciences, vol. 16, no. 4, pp. 516-527, 1989.

[62] P. L. McGeer, S. Itagaki, H. Tago, and E. G. McGeer, "Reactive microglia in patients with senile dementia of the Alzheimer type are positive for the histocompatibility glycoprotein HLA-DR," Neuroscience Letters, vol. 79, no. 1-2, pp. 195-200, 1987.
[63] J. Rogers, J. Luber-Narod, S. D. Styren, and W. H. Civin, "Expression of immune system-associated antigens by cells of the human central nervous system: relationship to the pathology of Alzheimer's disease," Neurobiology of Aging, vol. 9, no. 4, pp. 339-349, 1988.

[64] J. M. Rozemuller, P. Eikelenboom, S. T. Pals, and F. C. Stam, "Microglial cells around amyloid plaques in Alzheimer's disease express leucocyte adhesion molecules of the LFA-1 family," Neuroscience Letters, vol. 101, no. 3, pp. 288-292, 1989.

[65] P. L. McGeer, E. McGeer, J. Rogers, and J. Sibley, "Antiinflammatory drugs and Alzheimer disease," The Lancet, vol. 335, no. 8696, p. 1037, 1990.

[66] J. Rogers, L. C. Kirby, S. R. Hempelman et al., "Clinical trial of indomethacin in Alzheimer's disease," Neurology, vol. 43, no. 8, pp. 1609-1611, 1993.

[67] K. P. Townsend and D. Pratico, "Novel therapeutic opportunities for Alzheimer's disease: focus on nonsteroidal antiinflammatory drugs," The FASEB Journal, vol. 19, no. 12, pp. 1592-1601, 2005.

[68] D. T. Stephenson, C. A. Lemere, D. J. Selkoe, and J. A. Clemens, "Cytosolic phospholipase $\mathrm{A}_{2}\left(\mathrm{cPLA}_{2}\right)$ immunoreactivity is elevated in Alzheimer's disease brain," Neurobiology of Disease, vol. 3, no. 1, pp. 51-63, 1996.

[69] C. Chen, J. C. Magee, and N. G. Bazan, "Cyclooxygenase-2 regulates prostaglandin $\mathrm{E}_{2}$ signaling in hippocampal longterm synaptic plasticity," Journal of Neurophysiology, vol. 87, no. 6, pp. 2851-2857, 2002.

[70] C. Chen and N. G. Bazan, "Endogenous $\mathrm{PGE}_{2}$ regulates membrane excitability and synaptic transmission in hippocampal CA1 pyramidal neurons," Journal of Neurophysiology, vol. 93, no. 2, pp. 929-941, 2005.

[71] J. J. Hoozemans, A. J. Rozemuller, I. Janssen, C. J. De Groot, R. Veerhuis, and P. Eikelenboom, "Cyclooxygenase expression in microglia and neurons in Alzheimer's disease and control brain," Acta Neuropathologica, vol. 101, no. 1, pp. 2-8, 2001.

[72] K. Yasojima, C. Schwab, E. G. McGeer, and P. L. McGeer, "Distribution of cyclooxygenase-1 and cyclooxygenase-2 mRNAs and proteins in human brain and peripheral organs," Brain Research, vol. 830, no. 2, pp. 226-236, 1999.

[73] U. Chaudhry, H. Zhuang, and S. Dore, "Microsomal prostaglandin E synthase-2: cellular distribution and expression in Alzheimer's disease," Experimental Neurology, vol. 223, no. 2, pp. 359-365, 2010.

[74] U. A. Chaudhry, H. Zhuang, B. J. Crain, and S. Dore, "Elevated microsomal prostaglandin-E synthase-1 in Alzheimer's disease," Alzheimer's and Dementia, vol. 4, no. 1, pp. 6-13, 2008.

[75] T. J. Montine, K. R. Sidell, B. C. Crews et al., "Elevated CSF prostaglandin $\mathrm{E}_{2}$ levels in patients with probable AD," Neurology, vol. 53, no. 7, pp. 1495-1498, 1999.

[76] T. Hoshino, T. Namba, M. Takehara et al., "Prostaglandin $\mathrm{E}_{2}$ stimulates the production of amyloid- $\beta$ peptides through internalization of the $\mathrm{EP}_{4}$ receptor," Journal of Biological Chemistry, vol. 284, no. 27, pp. 18493-18502, 2009.

[77] R. K. Lee, S. Knapp, and R. J. Wurtman, "Prostaglandin $\mathrm{E}_{2}$ stimulates amyloid precursor protein gene expression: inhibition by immunosuppressants," Journal of Neuroscience, vol. 19, no. 3, pp. 940-947, 1999.

[78] A. M. Pooler, A. A. Arjona, R. K. Lee, and R. J. Wurtman, "Prostaglandin $\mathrm{E}_{2}$ regulates amyloid precursor protein expression via the EP2 receptor in cultured rat microglia," Neuroscience Letters, vol. 362, no. 2, pp. 127-130, 2004. 
[79] T. Hoshino, T. Nakaya, T. Homan et al., "Involvement of prostaglandin $\mathrm{E}_{2}$ in production of amyloid- $\beta$ peptides both in vitro and in vivo," Journal of Biological Chemistry, vol. 282, no. 45, pp. 32676-32688, 2007.

[80] L. A. Kotilinek, M. A. Westerman, Q. Wang et al., "Cyclooxygenase- 2 inhibition improves amyloid- $\beta$-mediated suppression of memory and synaptic plasticity," Brain, vol. 131, no. 3, pp. 651-664, 2008.

[81] A. Savonenko, P. Munoz, T. Melnikova et al., "Impaired cognition, sensorimotor gating, and hippocampal longterm depression in mice lacking the prostaglandin $\mathrm{E}_{2} \mathrm{EP} 2$ receptor," Experimental Neurology, vol. 217, no. 1, pp. 63-73, 2009.

[82] N. Iwamoto, K. Kobayashi, and K. Kosaka, "The formation of prostaglandins in the postmortem cerebral cortex of Alzheimer-type dementia patients," Journal of Neurology, vol. 236, no. 2, pp. 80-84, 1989.

[83] T. T. Rohn, S. M. Wong, C. W. Cotman, and D. H. Cribbs, "15-Deoxy- $\Delta 12,14$-prostaglandin $\mathrm{J}_{2}$, a specific ligand for peroxisome proliferator-activated receptor- $\gamma$, induces neuronal apoptosis," NeuroReport, vol. 12, no. 4, pp. 839-843, 2001.

[84] K. Takata, Y. Kitamura, M. Umeki et al., "Possible involvement of small oligomers of amyloid- $\beta$ peptides in 15deoxy- $\Delta^{12,14}$ prostaglandin $\mathrm{J}_{2}$-sensitive microglial activation," Journal Pharmacological Sciences, vol. 91, no. 4, pp. 330-333, 2003.

[85] H. Chen, S. M. Zhang, M. A. Hernan et al., "Nonsteroidal anti-inflammatory drugs and the risk of Parkinson disease," Archives of Neurology, vol. 60, no. 8, pp. 1059-1064, 2003.

[86] Y. C. Chung, H. W. Ko, E. Bok et al., "The role of neuroinflammation on the pathogenesis of Parkinson's disease," $B M B$ Reports, vol. 43, no. 4, pp. 225-232, 2010.

[87] A. MacHado, A. J. Herrera, J. L. Venero et al., "Peripheral inflammation increases the damage in animal models of nigrostriatal dopaminergic neurodegeneration: possible implication in parkinson's disease incidence," Parkinson's Disease, vol. 2011, Article ID 393769, 10 pages, 2011.

[88] E. C. Hirsch, "Glial cells and Parkinson's disease," Journal of Neurology, vol. 247, supplement 2, pp. II58-II62, 2000.

[89] G. W. Kreutzberg, "Principles of neuronal regeneration," Acta Neurochirurgica, vol. 66, pp. 103-106, 1996.

[90] P. Klivenyi, M. F. Beal, R. J. Ferrante et al., "Mice deficient in group IV cytosolic phospholipase $\mathrm{A}_{2}$ are resistant to MPTP neurotoxicity," Journal of Neurochemistry, vol. 71, no. 6, pp. 2634-2637, 1998.

[91] T. Hayakawa, M. C. Chang, S. I. Rapoport, and N. M. Appel, "Selective dopamine receptor stimulation differentially affects $\left[{ }^{3} \mathrm{H}\right]$ arachidonic acid incorporation, a surrogate marker for phospholipase $\mathrm{A}_{2}$-mediated neurotransmitter signal transduction, in a rodent model of Parkinson's disease," Journal of Pharmacology and Experimental Therapeutics, vol. 296, no. 3, pp. 1074-1084, 2001.

[92] A. Przybylkowski, I. Kurkowska-Jastrzebska, I. Joniec, A. Ciesielska, A. Czlonkowska, and A. Czlonkowski, "Cyclooxygenases mRNA and protein expression in striata in the experimental mouse model of Parkinson's disease induced by 1 methyl-4-phenyl-1,2,3,6-tetrahydropyridine administration to mouse," Brain Research, vol. 1019, no. 1-2, pp. 144-151, 2004.

[93] P. Teismann, K. Tieu, D. K. Choi et al., "Cyclooxygenase-2 is instrumental in Parkinson's disease neurodegeneration," Proceedings of the National Academy of Sciences of the United States of America, vol. 100, no. 9, pp. 5473-5478, 2003.
[94] T. Wang, Z. Pei, W. Zhang et al., "MPP'-induced COX2 activation and subsequent dopaminergic neurodegeneration," The FASEB Journal, vol. 19, no. 9, pp. 1134-1136, 2005.

[95] C. Knott, G. Stern, and G. P. Wilkin, "Inflammatory regulators in Parkinson's disease: iNOS, lipocortin-1, and cyclooxygenases-1 and -2," Molecular and Cellular Neuroscience, vol. 16, no. 6, pp. 724-739, 2000.

[96] P. Teismann, M. Vila, D. K. Choi et al., "COX-2 and neurodegeneration in Parkinson's disease," Annals of the New York Academy of Sciences, vol. 991, pp. 272-277, 2003.

[97] R. Sanchez-Pernaute, A. Ferree, O. Cooper, M. Yu, A. L. Brownell, and O. Isacson, "Selective COX-2 inhibition prevents progressive dopamine neuron degeneration in a rat model of Parkinson's disease," Journal of Neuroinflammation, vol. 1, article 6, 2004.

[98] P. Teismann and B. Ferger, "Inhibition of the cyclooxygenase isoenzymes COX-1 and COX-2 provide neuroprotection in the MPTP-mouse model of Parkinson's disease," Synapse, vol. 39, no. 2, pp. 167-174, 2001.

[99] R. Vijitruth, M. Liu, D. Y. Choi, X. V. Nguyen, R. L. Hunter, and G. Bing, "Cyclooxygenase-2 mediates microglial activation and secondary dopaminergic cell death in the mouse MPTP model of Parkinson's disease," Journal of Neuroinflammation, vol. 3, article 6, 2006.

[100] Z. Feng, D. Li, P. C. Fung, Z. Pei, D. B. Ramsden, and S. L. Ho, "COX-2-deficient mice are less prone to MPTP-neurotoxicity than wild-type mice," NeuroReport, vol. 14, no. 15, pp. 19271929, 2003.

[101] Z. H. Feng, T. G. Wang, D. D. Li et al., "Cyclooxygenase2-deficient mice are resistant to 1-methyl-4-phenyl1, 2, 3, 6-tetrahydropyridine-induced damage of dopaminergic neurons in the substantia nigra," Neuroscience Letters, vol. 329, no. 3, pp. 354-358, 2002.

[102] H. Chen, E. Jacobs, M. A. Schwarzschild et al., "Nonsteroidal antiinflammatory drug use and the risk for Parkinson's disease," Annals of Neurology, vol. 58, no. 6, pp. 963-967, 2005.

[103] J. A. Driver, G. Logroscino, L. Lu, J. M. Gaziano, and T. Kurth, "Use of non-steroidal anti-inflammatory drugs and risk of Parkinson's disease: nested case-control study," British Medical Journal, vol. 342, p. d198, 2011.

[104] A. Samii, M. Etminan, M. O. Wiens, and S. Jafari, "NSAID use and the risk of parkinsons disease: systematic review and meta-analysis of observational studies," Drugs and Aging, vol. 26, no. 9, pp. 769-779, 2009.

[105] E. Esposito, V. Di Matteo, A. Benigno, M. Pierucci, G. Crescimanno, and G. Di Giovanni, "Non-steroidal antiinflammatory drugs in Parkinson's disease," Experimental Neurology, vol. 205, no. 2, pp. 295-312, 2007.

[106] M. B. Mattammal, R. Strong, V. M. Lakshmi, H. D. Chung, and A. H. Stephenson, "Prostaglandin H synthetasemediated metabolism of dopamine: implication for Parkinson's disease," Journal of Neurochemistry, vol. 64, no. 4, pp. 1645-1654, 1995.

[107] W. Zhang, T. Wang, Z. Pei et al., "Aggregated $\alpha$-synuclein activates microglia: a process leading to disease progression in Parkinson's disease," The FASEB Journal, vol. 19, no. 6, pp. 533-542, 2005.

[108] I. Branchi, I. D’Andrea, M. Armida et al., "Striatal 6-OHDA lesion in mice: investigating early neurochemical changes underlying Parkinson's disease," Behavioural Brain Research, vol. 208, no. 1, pp. 137-143, 2010. 
[109] E. Carrasco, D. Casper, and P. Werner, "PGE 2 receptor EP1 renders dopaminergic neurons selectively vulnerable to lowlevel oxidative stress and direct $\mathrm{PGE}_{2}$ neurotoxicity," Journal of Neuroscience Research, vol. 85, no. 14, pp. 3109-3117, 2007.

[110] E. Carrasco, P. Werner, and D. Casper, "Prostaglandin receptor EP2 protects dopaminergic neurons against 6-OHDAmediated low oxidative stress," Neuroscience Letters, vol. 441, no. 1, pp. 44-49, 2008.

[111] J. Jin, F. S. Shie, J. Liu et al., "Prostaglandin $E_{2}$ receptor subtype 2 (EP2) regulates microglial activation and associated neurotoxicity induced by aggregated $\alpha$-synuclein," Journal of Neuroinflammation, vol. 4, article 2, 2007.

[112] G. Aldini, M. Carini, G. Vistoli et al., "Identification of actin as a 15 -deoxy- $\Delta 12,14$-prostaglandin $\mathrm{J}_{2}$ target in neuroblastoma cells: mass spectrometric, computational, and functional approaches to investigate the effect on cytoskeletal derangement," Biochemistry, vol. 46, no. 10, pp. 2707-2718, 2007.

[113] K. D. Ogburn and M. E. Figueiredo-Pereira, "Cytoskeleton/endoplasmic reticulum collapse induced by prostaglandin $\mathrm{J}_{2}$ parallels centrosomal deposition of ubiquitinated protein aggregates," Journal of Biological Chemistry, vol. 281, no. 32, pp. 23274-23284, 2006.

[114] Z. Li, F. Melandri, I. Berdo et al., " $\Delta$ 12-Prostaglandin $\mathrm{J}_{2}$ inhibits the ubiquitin hydrolase UCH-L1 and elicits ubiquitin-protein aggregation without proteasome inhibition," Biochemical and Biophysical Research Communications, vol. 319, no. 4, pp. 1171-1180, 2004.

[115] L. M. Koharudin, H. Liu, R. Di Maio, R. B. Kodali, S. H. Graham, and A. M. Gronenborn, "Cyclopentenone prostaglandin-induced unfolding and aggregation of the Parkinson disease-associated UCH-L1," Proceedings of the National Academy of Sciences of the United States of America, vol. 107, no. 15, pp. 6835-6840, 2010.

[116] X. Wang, Z. H. Qin, Y. Leng et al., "Prostaglandin A1 inhibits rotenone-induced apoptosis in SH-SY5Y cells," Journal of Neurochemistry, vol. 83, no. 5, pp. 1094-1102, 2002.

[117] L. Lacomblez, G. Bensimon, P. N. Leigh, P. Guillet, and V. Meininger, "Dose-ranging study of riluzole in amyotrophic lateral sclerosis," The Lancet, vol. 347, no. 9013, pp. 14251431, 1996.

[118] J. P. Julien, "Amyotrophic lateral sclerosis: unfolding the toxicity of the misfolded," Cell, vol. 104, no. 4, pp. 581-591, 2001.

[119] K. Moisse and M. J. Strong, "Innate immunity in amyotrophic lateral sclerosis," Biochimica et Biophysica Acta, vol. 1762, no. 11-12, pp. 1083-1093, 2006.

[120] M. Kiaei, K. Kipiani, S. Petri et al., "Integrative role of cPLA $_{2}$ with COX-2 and the effect of non-steriodal antiinflammatory drugs in a transgenic mouse model of amyotrophic lateral sclerosis," Journal of Neurochemistry, vol. 93, no. 2, pp. 403-411, 2005.

[121] D. Stephenson, K. Rash, B. Smalstig et al., "Cytosolic phospholipase $A_{2}$ is induced in reactive glia following different forms of neurodegeneration," Glia, vol. 27, pp. 110-128, 1999.

[122] N. Shibata, A. Kakita, H. Takahashi et al., "Increased expression and activation of cytosolic phospholipase $A_{2}$ in the spinal cord of patients with sporadic amyotrophic lateral sclerosis," Acta Neuropathologica, vol. 119, no. 3, pp. 345-354, 2010.

[123] G. Almer, C. Guegan, P. Teismann et al., "Increased expression of the pro-inflammatory enzyme cyclooxygenase-2 in amyotrophic lateral sclerosis," Annals of Neurology, vol. 49, no. 2, pp. 176-185, 2001.

[124] X. Liang, Q. Wang, J. Shi et al., "The prostaglandin $E_{2}$ EP2 receptor accelerates disease progression and inflammation in a model of amyotrophic lateral sclerosis," Annals of Neurology, vol. 64, no. 3, pp. 304-314, 2008.

[125] G. Almer, P. Teismann, Z. Stevic et al., "Increased levels of the pro-inflammatory prostaglandin $\mathrm{PGE}_{2}$ in CSF from ALS patients," Neurology, vol. 58, no. 8, pp. 1277-1279, 2002.

[126] K. Yasojima, W. W. Tourtellotte, E. G. McGeer, and P. L. McGeer, "Marked increase in cyclooxygenase-2 in ALS spinal cord: Implications for therapy," Neurology, vol. 57, no. 6, pp. 952-956, 2001.

[127] C. Maihofner, S. Probst-Cousin, M. Bergmann, W. Neuhuber, B. Neundorfer, and D. Heuss, "Expression and localization of cyclooxygenase-1 and -2 in human sporadic amyotrophic lateral sclerosis," European Journal of Neuroscience, vol. 18 , no. 6 , pp. 1527-1534, 2003.

[128] D.B. Drachman and J.D. Rothstein, "Inhibition of cyclooxygenase-2 protects motor neurons in an organotypic model of amyotrophic lateral sclerosis," Annals of Neurology, vol. 48, no. 5, pp. 792-795, 2000.

[129] M. F. Azari, C. Profyris, M. R. Le Grande et al., "Effects of intraperitoneal injection of Rofecoxib in a mouse model of ALS," European Journal of Neurology, vol. 12, no. 5, pp. 357364, 2005.

[130] D. B. Drachman, K. Frank, M. Dykes-Hoberg et al., "Cyclooxygenase 2 inhibition protects motor neurons and prolongs survival in a transgenic mouse model of ALS," Annals of Neurology, vol. 52, no. 6, pp. 771-778, 2002.

[131] P. N. Pompl, L. Ho, M. Bianchi, T. McManus, W. Qin, and G. M. Pasinetti, "A therapeutic role for cyclooxygenase2 inhibitors in a transgenic mouse model of amyotrophic lateral sclerosis," The FASEB Journal, vol. 17, no. 6, pp. 725727, 2003.

[132] L. Minghetti, "Cyclooxygenase-2 (COX-2) in inflammatory and degenerative brain diseases," Journal of Neuropathology \& Experimental Neurology, vol. 63, no. 9, pp. 901-910, 2004.

[133] P. Bezzi, G. Carmignoto, L. Pasti et al., "Prostaglandins stimulate calcium-dependent glutamate release in astrocytes," Nature, vol. 391, no. 6664, pp. 281-285, 1998.

[134] G. Almer, H. Kikuchi, P. Teismann, and S. Przedborski, "Is prostaglandin $\mathrm{E}_{2}$ a pathogenic factor in amyotrophic lateral sclerosis?" Annals of Neurology, vol. 59, no. 6, pp. 980-983, 2006.

[135] J. Iłzecka, "Prostaglandin $\mathrm{E}_{2}$ is increased in amyotrophic lateral sclerosis patients," Acta Neurologica Scandinavica, vol. 108, no. 2, pp. 125-129, 2003.

[136] M. Bilak, L. Wu, Q. Wang et al., " $\mathrm{PGE}_{2}$ receptors rescue motor neurons in a model of amyotrophic lateral sclerosis," Annals of Neurology, vol. 56, no. 2, pp. 240-248, 2004.

[137] J. H. Shin, Y. A. Lee, J. K. Lee et al., "Concurrent blockade of free radical and microsomal prostaglandin E synthase-1mediated PGE(2) production improves safety and efficacy in a mouse model of amyotrophic lateral sclerosis," Journal of Neurochemistry. In press.

[138] M. Kondo, T. Shibata, T. Kumagai et al., "15-Deoxy- $\Delta^{12,14}$ prostaglandin $\mathrm{J}_{2}$ : the endogenous electrophile that induces neuronal apoptosis," Proceedings of the National Academy of Sciences of the United States of America, vol. 99, no. 11, pp. 7367-7372, 2002.

[139] H. Y. Hsiao and Y. Chern, "Targeting glial cells to elucidate the pathogenesis of huntington's disease," Molecular Neurobiology, vol. 41, no. 2-3, pp. 248-255, 2010. 
[140] F. O. Walker, "Huntington's disease," Seminars in Neurology, vol. 27, no. 2, pp. 143-150, 2007.

[141] T. Moller, "Neuroinflammation in Huntington's disease," Journal of Neural Transmission, vol. 117, no. 8, pp. 1001-1008, 2010.

[142] L. Ma, A. J. Morton, and L. F. Nicholson, "Microglia density decreases with age in a mouse model of Huntington's disease," Glia, vol. 43, no. 3, pp. 274-280, 2003.

[143] E. Sapp, K. B. Kegel, N. Aronin et al., "Early and progressive accumulation of reactive microglia in the Huntington disease brain," Journal of Neuropathology \& Experimental Neurology, vol. 60, no. 2, pp. 161-172, 2001.

[144] P. Guidetti and R. Schwarcz, "3-Hydroxykynurenine and quinolinate: pathogenic synergism in early grade huntington's disease?" Advances in Experimental Medicine and Biology, vol. 527, pp. 137-145, 2003.

[145] A. C. Ludolph, F. He, P. S. Spencer, J. Hammerstad, and M. Sabri, "3-Nitropropionic acid-exogenous animal neurotoxin and possible human striatal toxin," Canadian Journal of Neurological Sciences, vol. 18, no. 4, pp. 492-498, 1991.

[146] M. E. Olds, D. B. Jacques, and O. Kopyov, "Behavioral and anatomical effects of quinolinic acid in the striatum of the hemiparkinsonian rat," Synapse, vol. 55, no. 1, pp. 26-36, 2005.

[147] J. K. Ryu, H. B. Choi, and J. G. McLarnon, "Combined minocycline plus pyruvate treatment enhances effects of each agent to inhibit inflammation, oxidative damage, and neuronal loss in an excitotoxic animal model of Huntington's disease," Neuroscience, vol. 141, no. 4, pp. 1835-1848, 2006.

[148] H. Kalonia and A. Kumar, "Suppressing inflammatory cascade by cyclo-oxygenase inhibitors attenuates quinolinic acid induced Huntington's disease-like alterations in rats," Life Sciences, vol. 88, no. 17-18, pp. 784-791, 2011.

[149] H. Kalonia, P. Kumar, A. Kumar, and B. Nehru, "Effects of caffeic acid, rofecoxib, and their combination against quinolinic acid-induced behavioral alterations and disruption in glutathione redox status," Neuroscience Bulletin, vol. 25, no. 6, pp. 343-352, 2009.

[150] H. Kalonia, P. Kumar, A. Kumar, and B. Nehru, "Protective effect of rofecoxib and nimesulide against intra-striatal quinolinic acid-induced behavioral, oxidative stress and mitochondrial dysfunctions in rats," NeuroToxicology, vol. 31, no. 2, pp. 195-203, 2010.

[151] P. Kumar, S. S. Padi, P. S. Naidu, and A. Kumar, "Cyclooxygenase inhibition attenuates 3-nitropropionic acid-induced neurotoxicity in rats: possible antioxidant mechanisms," Fundamental and Clinical Pharmacology, vol. 21, no. 3, pp. 297-306, 2007.

[152] F. Norflus, A. Nanje, C. A. Gutekunst et al., "Antiinflammatory treatment with acetylsalicylate or rofecoxib is not neuroprotective in Huntington's disease transgenic mice," Neurobiology of Disease, vol. 17, no. 2, pp. 319-325, 2004.

[153] G. Schilling, A. V. Savonenko, M. L. Coonfield et al., "Environmental, pharmacological, and genetic modulation of the HD phenotype in transgenic mice," Experimental Neurology, vol. 187, no. 1, pp. 137-149, 2004.

[154] K. Bantubungi, C. Jacquard, A. Greco et al., "Minocycline in phenotypic models of Huntington's disease," Neurobiology of Disease, vol. 18, no. 1, pp. 206-217, 2005.

[155] P. Kumar, H. Kalonia, and A. Kumar, "Role of LOX/COX pathways in 3-nitropropionic acid-induced Huntington's disease-like symptoms in rats: protective effect of licofelone," British Journal of Pharmacology, vol. 164, pp. 644-654, 2011.
[156] L. Minghetti, A. Greco, R. L. Potenza et al., "Effects of the adenosine $\mathrm{A}_{2} \mathrm{~A}$ receptor antagonist $\mathrm{SCH} 58621$ on cyclooxygenase- 2 expression, glial activation, and brainderived neurotrophic factor availability in a rat model of striatal neurodegeneration," Journal of Neuropathology \& Experimental Neurology, vol. 66, no. 5, pp. 363-371, 2007.

[157] H. Slawik, B. Volk, B. Fiebich, and M. Hull, "Microglial expression of prostaglandin EP3 receptor in excitotoxic lesions in the rat striatum," Neurochemistry International, vol. 45, no. 5, pp. 653-660, 2004.

[158] Z. H. Qin, Y. Wang, R. W. Chen et al., "Prostaglandin $A_{1}$ protects striatal neurons against excitotoxic injury in rat striatum," Journal of Pharmacology and Experimental Therapeutics, vol. 297, no. 1, pp. 78-87, 2001.

[159] D. L. Krause and N. Muller, "Neuroinflammation, microglia and implications for anti-inflammatory treatment in Alzheimer's disease," International Journal of Alzheimer's Disease, vol. 2010, Article ID 732806, 9 pages, 2010.

[160] T. C. Frank-Cannon, L. T. Alto, F. E. McAlpine, and M. G. Tansey, "Does neuroinflammation fan the flame in neurodegenerative diseases?" Molecular Neurodegeneration, vol. 4, no. 1, article 47, 2009.

[161] W. J. Streit, "Microglial senescence: does the brain's immune system have an expiration date?" Trends in Neurosciences, vol. 29, no. 9, pp. 506-510, 2006.

[162] M. L. Block, L. Zecca, and J. S. Hong, "Microgliamediated neurotoxicity: uncovering the molecular mechanisms," Nature Reviews Neuroscience, vol. 8, no. 1, pp. 57-69, 2007.

[163] B. Hauss-Wegrzyniak, P. Dobrzanski, J. D. Stoehr, and G. L. Wenk, "Chronic neuroinflammation in rats reproduces components of the neurobiology of Alzheimer's disease," Brain Research, vol. 780, no. 2, pp. 294-303, 1998.

[164] T. Farooqui and A. A. Farooqui, "Lipid-mediated oxidative stress and inflammation in the pathogenesis of Parkinson's disease," Parkinson's Disease, vol. 2011, Article ID 247467, 9 pages, 2011.

[165] S. E. Hickman, E. K. Allison, and J. El Khoury, "Microglial dysfunction and defective $\beta$-amyloid clearance pathways in aging Alzheimer's disease mice," Journal of Neuroscience, vol. 28, no. 33, pp. 8354-8360, 2008.

[166] X. G. Luo, J. Q. Ding, and S. D. Chen, "Microglia in the aging brain: relevance to neurodegeneration," Molecular Neurodegeneration, vol. 5, no. 1, article 12, 2010.

[167] L. Qian, P. M. Flood, and J. S. Hong, "Neuroinflammation is a key player in Parkinson's disease and a prime target for therapy," Journal of Neural Transmission, vol. 117, no. 8, pp. 971-979, 2010. 


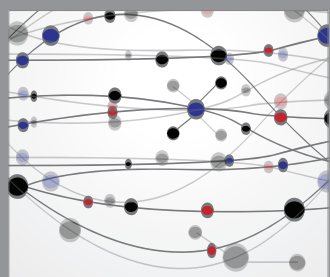

The Scientific World Journal
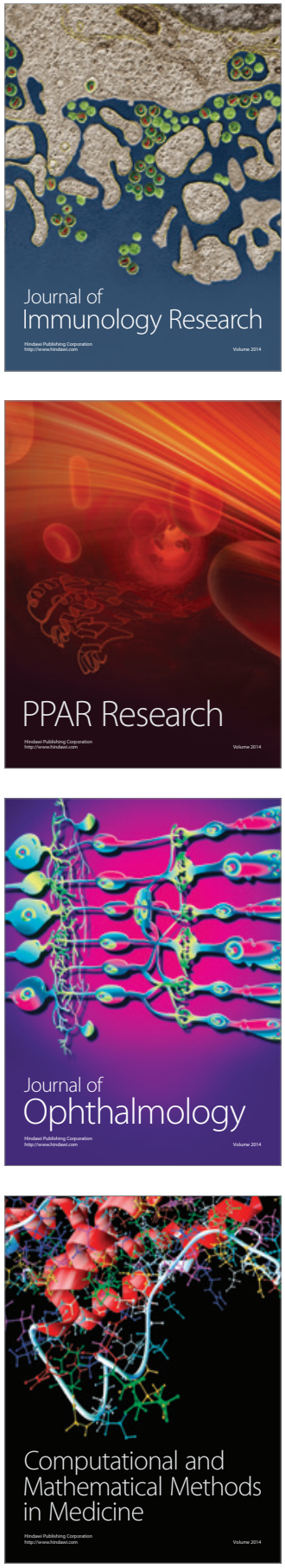

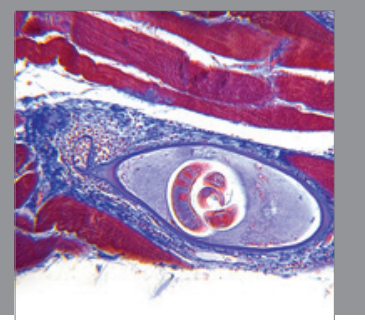

Gastroenterology

Research and Practice
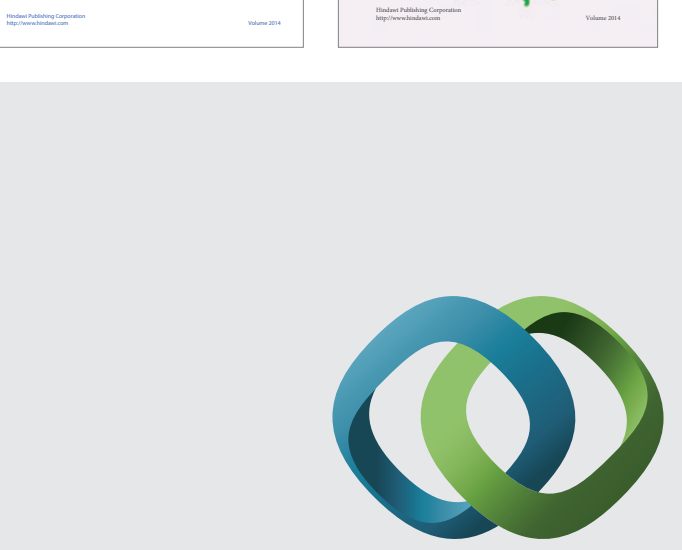

\section{Hindawi}

Submit your manuscripts at

http://www.hindawi.com
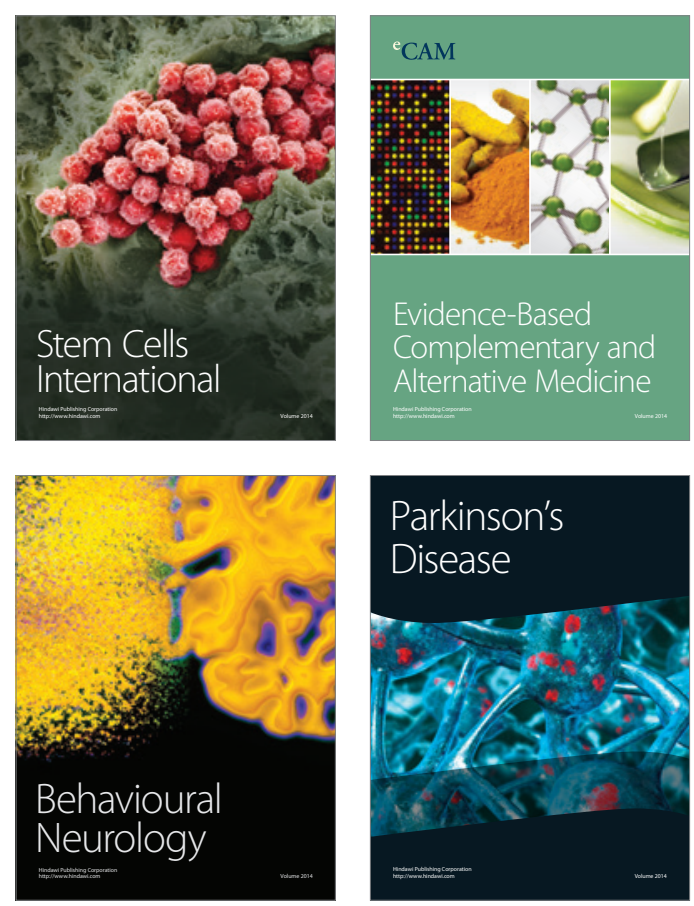

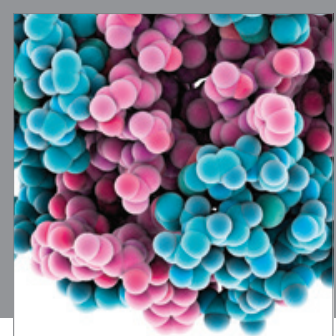

Journal of
Diabetes Research

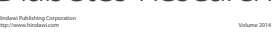

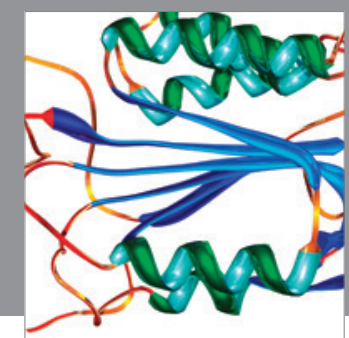

Disease Markers
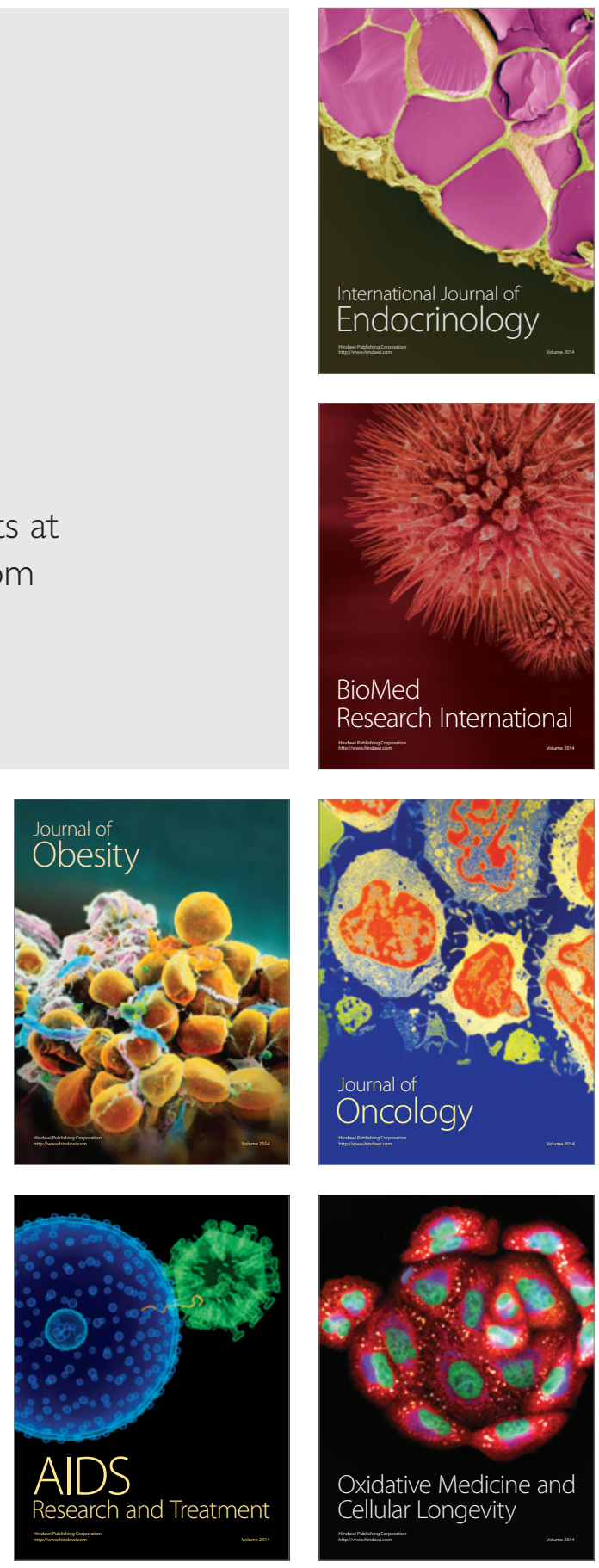